\title{
PETA DIGITAL BERBASIS KOMUNITAS DENGAN INASAFE
}

\author{
Destryn Jacob ${ }^{1}$, Joyce Christian Kumaat ${ }^{2}$, Selvana T. R. Tewal ${ }^{2}$ \\ ${ }^{1}$ Mahasiswa Program Studi Geografi, Fakultas Ilmu Sosial, Universitas Negeri Manado \\ ${ }^{2}$ Program Studi Geografi, Fakultas Ilmu Sosial, Universitas Negeri Manado \\ e-mail: selvanatewal@unima.ac.id
}

\begin{abstract}
Volcano eruption is one of many natural events that can cause natural disasters. This study aims to map the number of buildings, calculate building losses and calculate the logistics needed when a Lokon volcanic eruption occurs. The research method used is quantitative using a spatial analysis approach (Geographic Information System). Data collection techniques using secondary data collection techniques. The technique used in this study is the analysis of the hazard data of the Lokon volcano eruption, OpenStreetMap building data, losses and logistics. Data analysis was processed on Quantum GIS Software by using the InaSAFE plugin to produce a zoning map of volcanic eruption hazards, affected buildings, building losses and logistical estimates. The results of the study are the zoning of Lokon volcano eruption into 2 zones, low and high zones. The results of the calculation of volcanic eruption exposure treated with the InaSAFE plugin based on hazard zoning resulted in the total number of buildings affected, namely in a $3.5 \mathrm{~km}$ radius prone area with 202 buildings for high threat areas and 555 buildings for low threat areas and for vulnerable areas $5 \mathrm{~km}$ radius disaster totaling 55 buildings for high threat areas and 7,300 buildings for low threat areas. The results of the analysis of the number of losses in a $3.5 \mathrm{~km}$ radius prone area is 757 buildings $R p .36,636,840,000$ and for disaster-prone areas with a radius of 5 KM of 7,355 buildings Rp. 158,730,660,000. The results of the logistical analysis are based on the estimated exposure to residents who need evacuation where there are 36,300 inhabitants who live in low to high disasterprone areas. From the total population affected, the estimated minimum basic need for rice is 98,010 liters, 629,805 liters of drinking water, 2,413,224 liters of clean water and 1,815 units of toilets.
\end{abstract}

Keywords: Volcanic eruptions, QGIS, InaSAFE

\begin{abstract}
Abstrak: Letusan gunung api merupakan satu dari sekian banyak peristiwa alam yang dapat menyebabkan timbulnya bencana alam. Penelitian ini bertujuan untuk memetakan jumlah bangunan, menghitung kerugian bangunan serta menghitung logistik yang dibutuhkan ketika terjadi bencana letusan gunung api Lokon. Metode penelitian yang digunakan adalah kuantitatif dengan menggunakan pendekatan analisis keruangan (spatial analysis) dalam Sistem Informasi Geografis (SIG). Teknik pengumpulan data menggunakan teknik pengumpulan data sekunder. Teknik yang digunakan dalam penelitian ini adalah analisis data bahaya (hazard) letusan gunung api Lokon, data bangunan OpenStreetMap, kerugian dan logistik. Analisis data diolah pada Sofware Quantum GIS dengan menggunakan plugin InaSAFE menghasilkan peta zonasi bahaya letusan gunungapi, bangunan terdampak, kerugian per bangunan serta estimasi logistik. Hasil penelitian adalah pengklasifikasian zonasi letusan gunung api Lokon menjadi 2 zona yaitu zona rendah dan tinggi. Hasil penghitungan Keterpaparan letusan gunung api yang diolah dengan plugin InaSAFE berdasarkan zonasi bahaya (hazard) menghasilkan jumlah total bangunan terdampak yaitu pada kawasan rawan bencana radius 3,5 KM berjumlah 202 bangunan untuk area ancaman tinggi dan 555 bangunan untuk area ancaman rendah dan untuk kawasan rawan bencana radius 5 KM berjumlah 55 bangunan untuk area ancaman tinggi dan 7.300 bangunan untuk area ancaman rendah. Hasil analisis jumlah kerugian pada kawasan rawan bencana radius 3,5 KM yaitu 757 bangunan Rp. 36.636.840.000 dan untuk kawasan rawan bencana radius 5 KM yaitu 7.355 bangunan Rp. 158.730.660.000. Hasil analisis logistik didasarkan pada estimasi keterpaparan terhadap penduduk yang memerlukan evakuasi dimana terdapat 36.300 jiwa penduduk yang berada pada kawasan rawan bencana rendah hingga tinggi. Dari jumlah penduduk yang terdampak maka didapat estimasi kebutuhan dasar minimum beras sebanyak 98.010 liter, air minum sebanyak 629.805 liter, air bersih sebanyak 2.413.224 liter dan toilet sebanyak 1.815 unit.
\end{abstract}

Kata Kunci: darurat, tiba-tiba, teknologi, geospasial, geo-informasi 


\section{PENDAHULUAN}

Bencana adalah peristiwa atau rangkaian peristiwa yang mengancam dan menggangu kehidupan dan penghidupan masyarakat yang disebabkan, baik oleh faktor alam dan/atau faktor non alam maupun faktor manusia sehingga mengakibatkan timbulnya korban jiwa manusia, kerusakan lingkungan, kerugian harta benda dan dampak psikologis (Undang-Undang Nomor 24 Tahun 2007 Pasal 1 Ayat 1 Tentang Penanggulangan Bencana).

Pada 14 Juli 2011 gunung Lokon di Kawah Tompaluan meletus dengan lontaran material pijar, pasir, dan hujan abu setinggi sekitar 1.500 meter. Dimana letusan ini mengakibatkan lebih dari 10.000 warga dibeberapa Desa diantaranya Kinilow, Tinoor dan Kakaskasen mengungsi kedaerah Tomohon dan Manado (Data Bencana Indonesia Tahun 2011, BNPB).Selanjutnya terjadi letusan pada 9 September 2013, dimana gunung Lokon melontarkan material vulkanis hingga ketinggian sekitar 1.500 meter dari kawah Tompaluan Lokon, material letusan berwarna hitam keabuan keluar dari kawah. Kejadian kali ini tidak menimbulkan kerugian atau korban jiwa, tetapi PVMBG masih menetapkan radius 2,5 km bagi masyarakat untuk tidak melakukan aktivitas disekitar kawah Tompaluan (https://www.voaindonesia.com/a/gunung-

lokon-di-sulawesi-utara-

meletus/1745768.html).

Melihat dari persoalan diatas, dimana gunungapi Lokon telah terjadi beberapa kali letusan, juga gunungapi Lokon merupakan gunungapi aktif yang bisa meletus kapan saja, maka dibutuhkan perhatian serta keseriusan bersama dari setiap stekolder untuk turut serta dalam upaya meminimalisir resiko ketika terjadi letusan gunungapi Lokon. Salah satunya ialah dengan pemanfaatan Sistem Informasi Geografis, dimana dalam hal ini akan menggunakan aplikasi Quantum Gis-Inasafe yang dapat memetakan daerah-daerah yang terdampak letusan, bangunan terpapar, serta dapat menghitung kerugian berdasarkan pada zona kawasan rawan bencana gunungapi Lokon.

Berdasarkan pada latar belakang masalah, maka peneliti terdorong untuk melakukan penelitian dengan judul : "Analisis Daerah Rawan Bencana Letusan Gunung Api Lokon, dengan Menggunakan Aplikasi Quantum GISInaSAFE"
Berdasarkan pada uraian latar belakang masalah, maka dapat diidentikasikan permasalahan penelitian yaitu:

1. Bangunan terdampak akibat erupsi gunungapi Lokon

2. Kerugian yang disebabkan oleh letusan gunungapi Lokon berupa kerugian material dan korban jiwa

3. Pemenuhan logistik selama masa pengungsian ketika terjadi bencana

Batasan masalah yang dikaji dalam penelitian ini yaitu :

1. Banyaknya bangunan yang terdampak letusan gunungapi Lokon

2. Perkiraan kerugian yang diakibatkan pada saat letusan gunungapi Lokon sangat tinggi

3. Pemenuhan logistik selama masa pengungsian ketika terjadi bencana

Rumusan Masalah

1. Berapa bangunan yang terdampak bencana letusan gunungapi Lokon?

2. Berapa perkiraan kerugian yang diakibatkan pada saat letusan gunungapi Lokon sangat tinggi?

3. Bagaimana pemenuhan logistik selama masa pengungsian ketika terjadi bencana?

Tujuan Penelitian

1. Memetakanperkiraan bangunan yang terdampak bencana letusan gunungapi Lokon

2. Menghitung perkiraan kerugian yang diakibatkan pada saat letusan gunungapi Lokon sangat tinggi

3. Menghitung perkiraan logistik yang dibutuhkan selama masa pengungsian ketika terjadi bencana

Penelitian ini dilakukan dengan harapan dapat memberikan manfaat serta informasi kepada Pemerintah dan masyarakat tentang banyaknya bangunan yang terdampak, kerugian yang diakibatkan oleh bencana letusan gunungapi Lokon, serta bagaimana pemenuhan logistik selama masa pengungsian ketika terjadi bencana.

\section{METODE}

Penelitian ini menggunakan metode pendekatan kuantitatif dengan menggunakan 
analisis keruangan (spatial analysis) dalam Sistem Informasi Geografi (SIG).

Variabel penelitian adalah suatu atribut atau sifat, nilai dari orang atau kegiatan yang mempunyai variasi tertentu yang ditetapkan oleh peneliti untuk dipelajari dan ditarik kesimpulan. Dalam penelitian ini terdapat tiga variabel, yaitu: 1) Bangunan yang terdampak, dalam penelitian ini, akan dianalisis bangunan mana yang terdampak akibat dari letusan gunungapi Lokon. 2) Kerugian, dalam hal ini akan menghitung jumlah kerugian dari setiap bangunan yang ada, sehingga ketika gunungapi Lokon meletus maka akan dapat diketahui berapa bangunan/rumah yang terdampak dan akan diketahui berapa perkiraan kerugian per satu bangunan. 3) Logistik, untuk logistik dalam penelitian ini, akan dianalisis bagaimana pemenuhan kebutuhan penduduk selama masa pengungsian ketika terjadi bencana, berdasarkan pada data penduduk yang terdampak dan yang mengungsi.

Dalam penelitian ini, data yang digunakan meliputi data primer (pengamatan lapangan) dan data sekunder.

1. Data Primer, data primer meliputi pengamatan lapangan pada beberapa titik lokasi penelitian dan bangunan.

2. Data Sekunder, data sekunder meliputi peta kota Tomohon, bahaya (hazard) letusan gunungapi kota Tomohon, data Badan Pusat Statistik dan data bangunan pada OpenStreetMap.

Teknik pengumpulan data menggunakan teknik pengumpulan data sekunder yang berasal dari instansi-instansi atau lembaga-lembaga terkait, perpustakaan ataupun arsip perorangan. Pengumpulan data tersebut kemudian dilanjutkan dengan survey lapangan untuk mendapatkan informasi sesuai dengan daftar catatan yang dibuat sekaligus penyesuaian dengan data sekunder.

Teknik analisis data dalam penelitian ini yaitu menggunakan teknik analisis data sekunder, dimana analisis data sekunder mempunyai pengertian, suatu strategi penelitian yang memanfaatkan data kuantitatif maupun kualitatif yang sudah ada untuk menemukan permasalahan baru atau untuk menguji hasil penelitian terdahulu (Heaton 2004, dinukil
Andrews, et.al., 2012). Analisis data sekunder dalam penelitian ini dikelola pada software Quantum GIS (QGIS) yang menyediakan toolbar plugins InaSAFE yang memiliki fungsi menganalisis data spasial bencana letusan gunungapi.

\section{HASIL DAN PEMBAHASAN}

\section{Keterpaparan Letusan Terhadap Bangunan}

Dari hasil analisis menggunakan plugin InaSAFE maka didapat hasil bangunan terdampak sebagai berikut:

a. Bangunan Terpapar dalam Kawasan Rawan Bencana Radius 3,5 KM

Berdasarkan Tabel 1, dapat dijelaskan bahwa pada kawasan rawan bencana radius 3,5 KM total perkiraan bangunan terpapar berjumlah 757, dengan pembagian per area ancaman yaitu tinggi, 202 bangunan dan rendah 555 bangunan. Dan untuk pembagian persebaran bangunan terpapar pada setiap Kelurahan.

Tabel 1. Perkiraan Jumlah Bangunan Terpapar per Area Ancaman

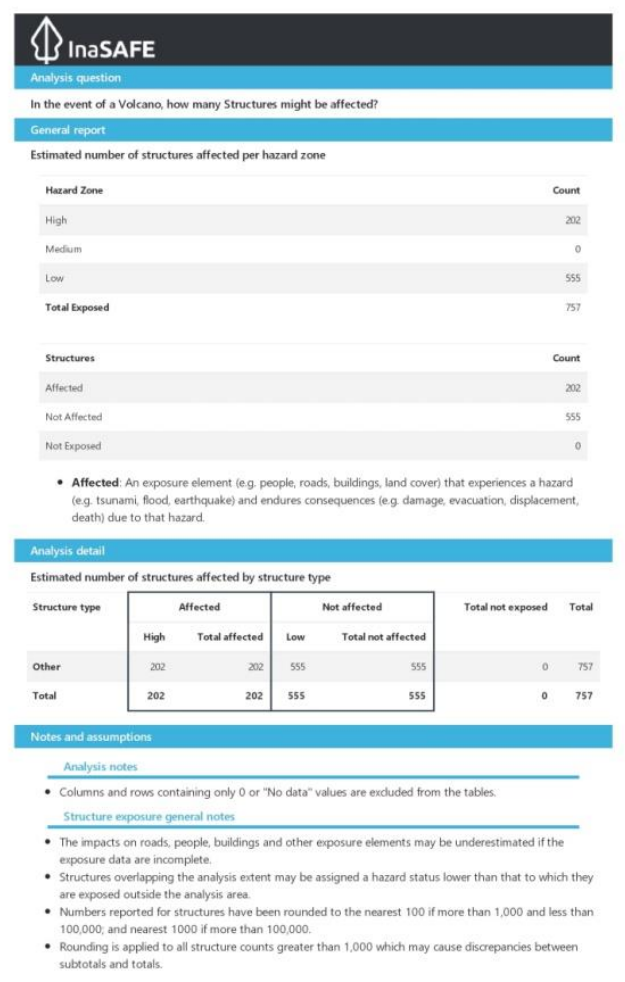




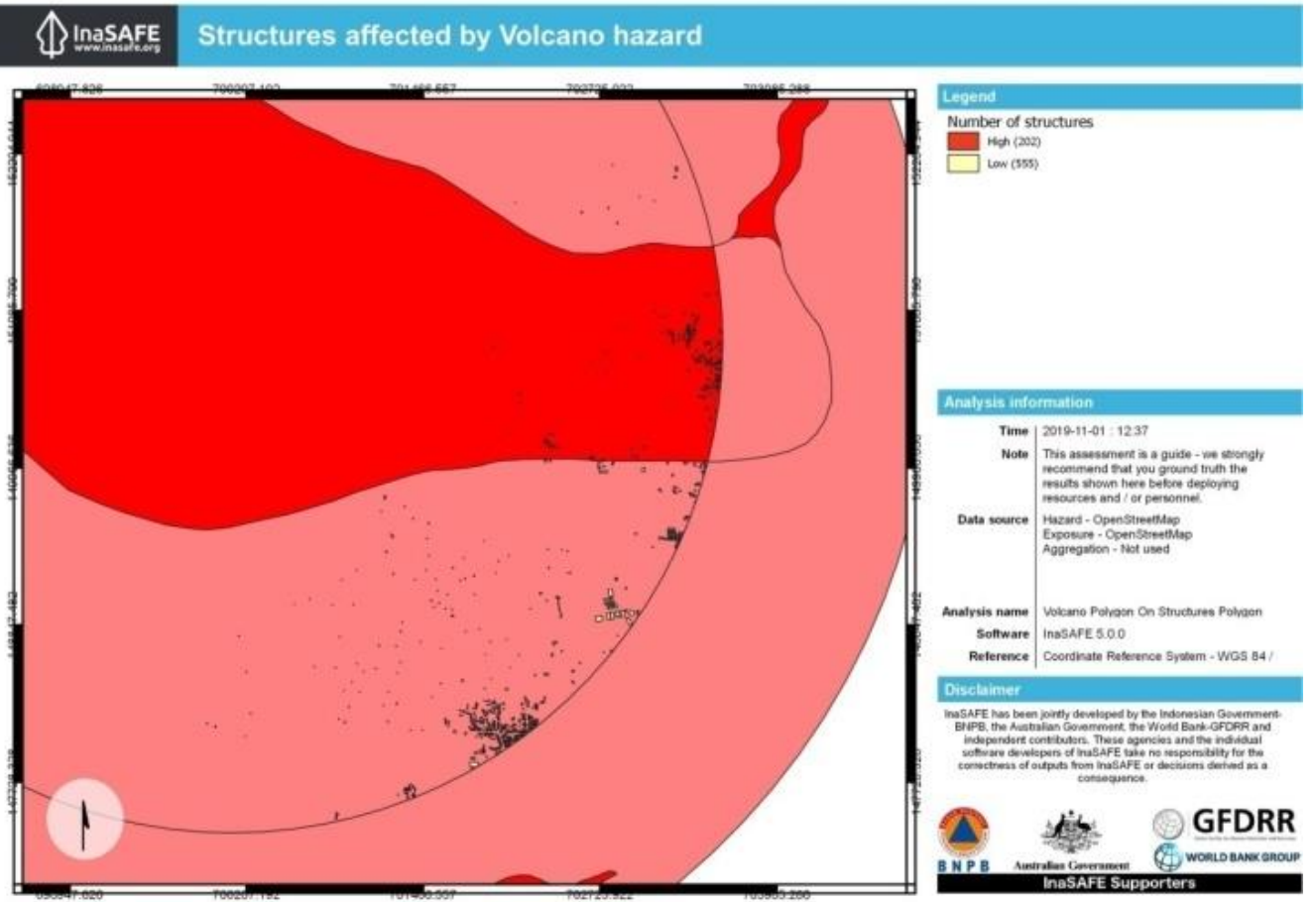

Gambar 1 Hasil Analisis Keterpaparan 3,5 km

b. Bangunan Terpapar Dalam Kawasan Rawan Bencana Radius $5 \mathrm{Km}$

Berdasarkan Tabel 2 dapat dijelaskan bahwa pada kawasan rawan bencana radius 5 $\mathrm{Km}$ total perkiraan bangunan terpapar berjumlah
7.355 bangunan, dengan pembagian per area ancaman yaitu tinggi 55 bangunan dan rendah 7.300 bangunan. Sementara untuk pembagian persebaran bangunan terpapar pada setiap Kelurahan.

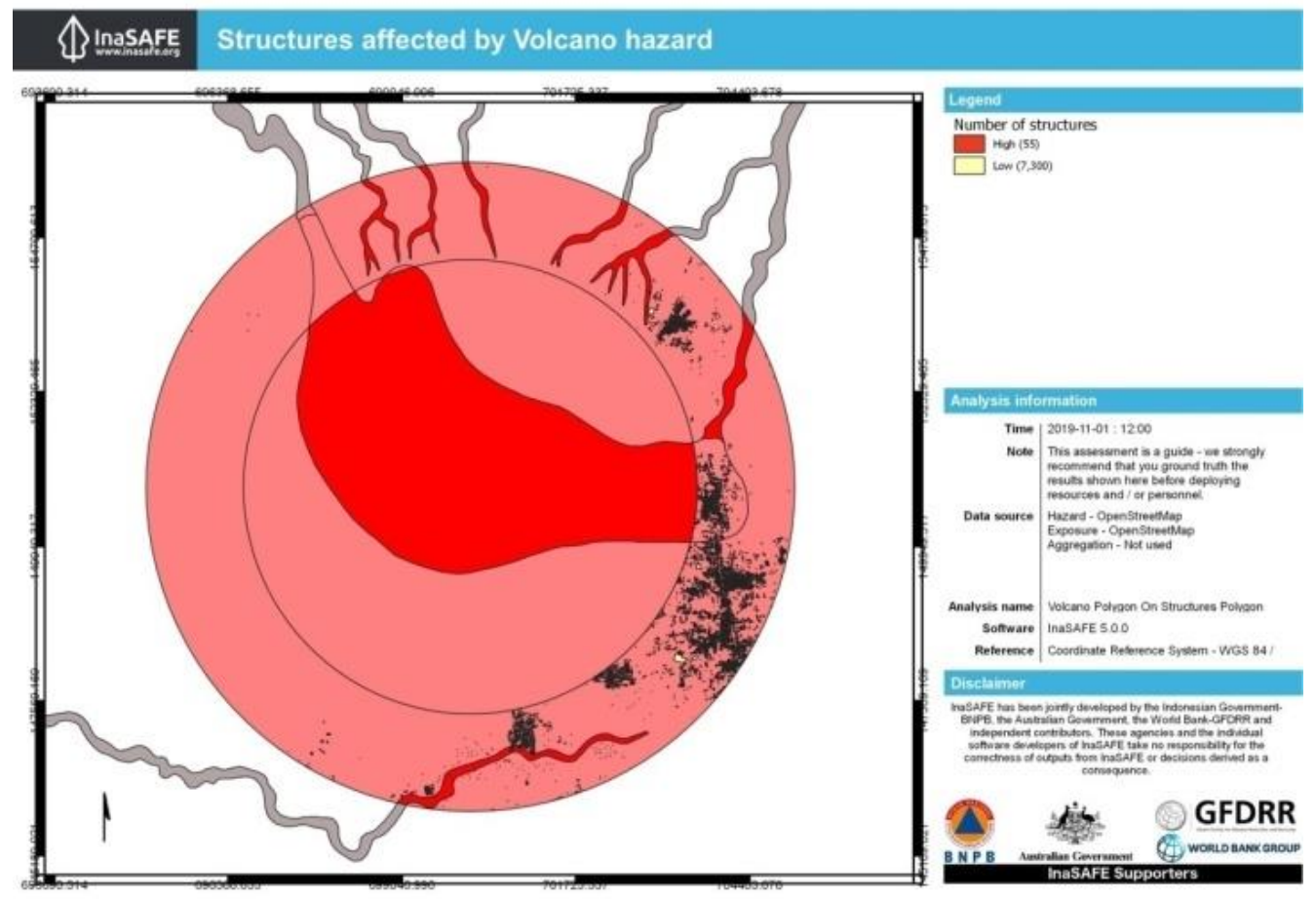

Gambar 2 Hasil Analisis Keterpaparan 5 km

Tabel 2. Perkiraan Jumlah Bangunan Terpapar Per Area Ancaman 


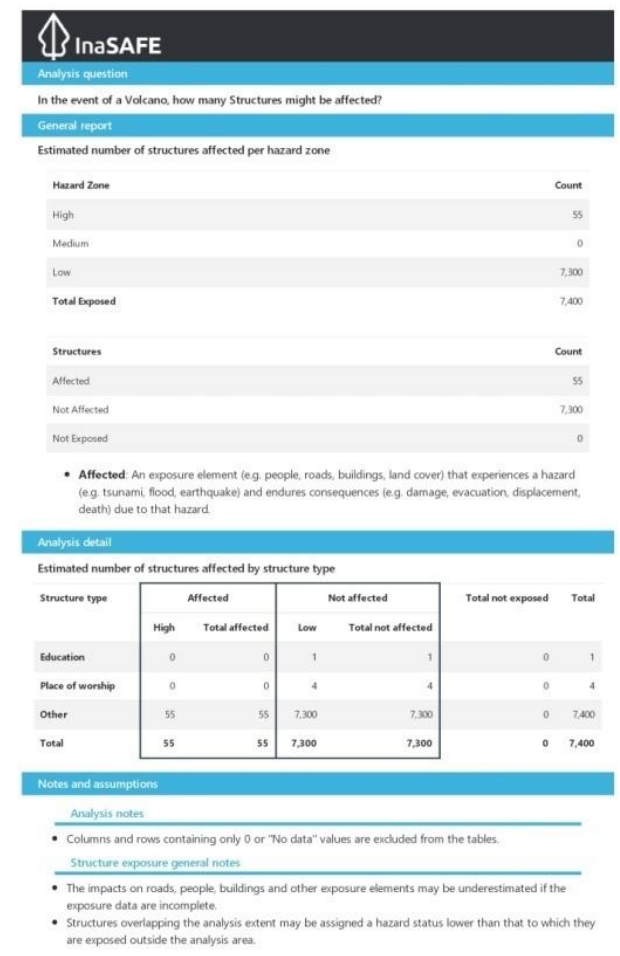

Perhitungan Nilai Kerugian Bangunan

Untuk mengetahui berapa besar jumlah kerugian per masing-masing bangunan, maka digunakan rumus perkalian antara luas bangunan dengan nilai kerugian yang telah ditetapkan oleh Badan Nasional Penanggulangan Bencana. Dimana rumusnya sebagai berikut:

\{"Size" *1800000* 0.7 (Untuk Kerugian Berat)\} \{"Size” *1800000* 0.1 (Untuk Kerugian Ringan)\}

Dari hasil analisis pada Quantum Gis dengan menggunakan kedua rumus diatas, maka didapat jumlah kerugian pada masing-masing bangunan terdampak yang dibagi berdasarkan Kelurahan, dan disajikan pada tabel dibawah.

Tabel 3. Jumlah Bangunan Terdampak dan Jumlah Kerugian Pada Kawasan Rawan Bencana Radius 3,5 Km

\begin{tabular}{llll}
\hline No. & Kelurahan & Jumlah & Jumlah Kerugian \\
\hline 1. & Kakaskasen Satu & 68 & Rp. 5.497.020.000 \\
2. & Kakaskasen Dua & 24 & Rp. 1.227 .960 .000 \\
3. & Kakaskasen Tiga & 97 & Rp. 2.860.380.000 \\
4. & Kayawu & 6 & Rp. 78.660.000 \\
5. & Kinilow & 129 & Rp. 14.946.120.000 \\
6. & Kinilow Satu & 48 & Rp. 5.702.760.000 \\
7. & Wailan & 376 & Rp. 6.323.940.000 \\
\hline & Jumlah & 748 & Rp. 36.636.840.000
\end{tabular}

Tabel 4. Jumlah Bangunan Terdampak dan Jumlah Kerugian Pada Kawasan Rawan Bencana Radius 5 Km

\begin{tabular}{llll}
\hline No. & Kelurahan & Jumlah & Jumlah Kerugian \\
\hline 1. & Kakaskasen & 660 & Rp. 13.979 .700 .000 \\
2. & Kakaskasen Satu & 708 & Rp. 17.961.120.000 \\
3. & Kakaskasen Dua & 1598 & Rp. 32.235.300.000 \\
4. & Kakaskasen Tiga & 1342 & Rp. 34.198.920.000 \\
5. & Kamasi & 1 & Rp. 52.920.000 \\
6. & Kamasi Satu & 2 & Rp. 7.560.000 \\
7. & Kayawu & 695 & Rp. 15.951.240.000 \\
8. & Kinilow & 614 & Rp. 10.785.420.000 \\
9. & Kinilow Satu & 488 & Rp. 7.673.400.000 \\
10. & Taratara & 8 & Rp. 99.360 .000 \\
11. & Taratara Tiga & 33 & Rp. 1.473.840.000 \\
12. & Tinoor Satu & 405 & Rp. 7.934.040.000 \\
13. & Tinoor Dua & 369 & Rp. 7.331.040.000 \\
14. & Wailan & 468 & Rp. 8.147.700.000 \\
15. & Woloan Satu Utara & 48 & Rp. 608.040.000 \\
16. & Woloan Dua & 28 & Rp. 291.060.000 \\
\hline & Jumlah & 7.467 & Rp. 158.730.660.000
\end{tabular}

\section{Estimasi Penduduk Terpapar dan Logistik}

Tabel 5. Hasil Analisis Perkiraan Jumlah Penduduk Terpapar dan Estimasi Kebutuhan Dasar Minimum

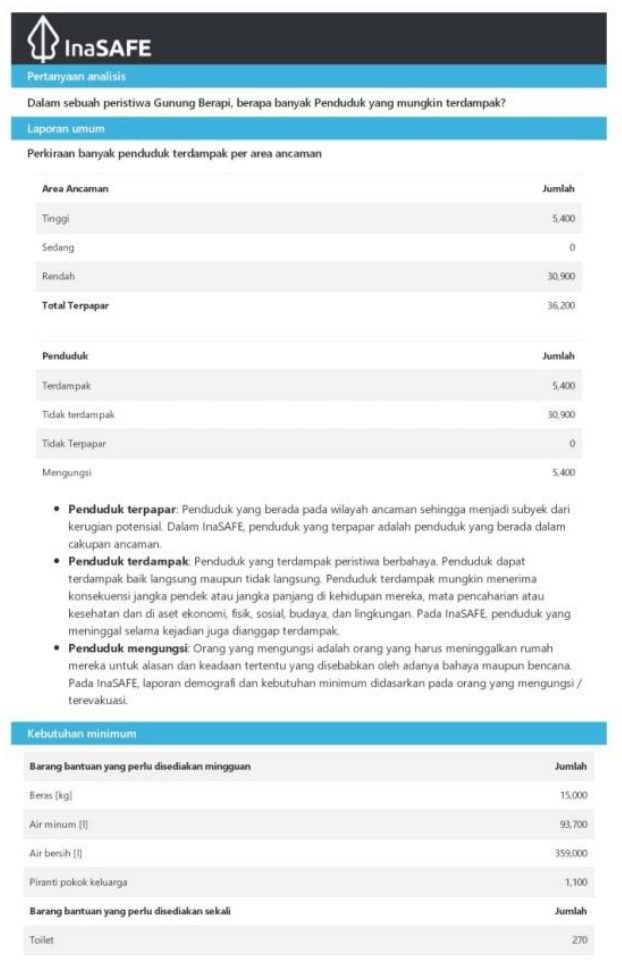

Berdasarkan Tabel 5 dapat dijelaskan bahwa estimasi penduduk terpapar akibat letusan gunungapi Lokon pada tiap kelas bahaya dikelompokkan berdasarkan klasifikasi bahaya yaitu kelas tinggi dan kelas rendah. 


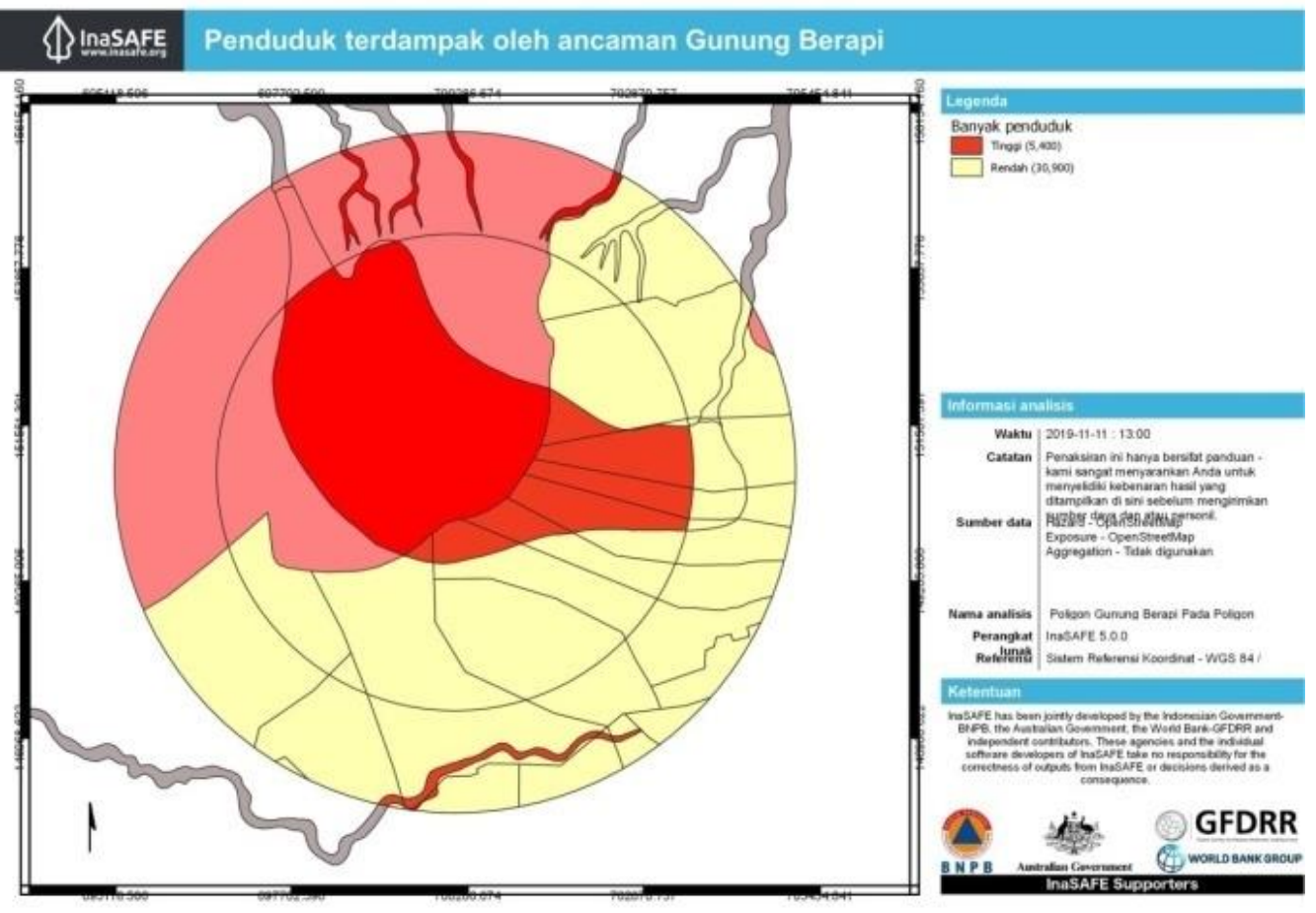

Gambar 1. Hasil Analisis Keterpaparan Letusan Gunung Api Terhadap Penduduk

Sedangkan pembagian per kelas bahaya dapat dilihat pada tabel 6 dibawah.

Tabel 6. Persebaran Jumlah Penduduk Terdampak Pada Tiap Kelas Bahaya Letusan Gunungapi

\begin{tabular}{lll}
\hline No & Kelas Bahaya & Jumlah (Jiwa) \\
\hline 1. & Tinggi & 5.400 \\
2. & Rendah & 30.900 \\
\hline
\end{tabular}

InaSAFE memiliki kemampuan yang sangat baik dalam mengestimasi jumlah kebutuhan dasar minimum yang diperlukan selama masa pengungsian akibat bencana letusan gunungapi yang terjadi. Estimasi kebutuhan dasar minimum ini didasarkan pada jumlah penduduk terdampak. Kebutuhan dasar minimum yang diperlukan terdiri dari kebutuhan dasar yang harus dipenuhi pada tiap minggu selama masa pengungsian (seperti: beras, air minum, air bersih dan toilet). Estimasi kebutuhan dasar minimum disajikan pada tabel 7 dibawah ini.

Tabel 7. Estimasi Jumlah Kebutuhan Dasar Minimum

\begin{tabular}{lllll}
\hline No. & Kebutuhan & Satuan & Jumlah & Jumlah (Bulan) \\
\hline 1. & Beras & Kilogram $(\mathrm{Kg})$ & 98.010 & 329.040 \\
2. & Air Minum & Liter $(\mathrm{L})$ & 629.805 & 2.519 .220 \\
3. & Air Bersih & Liter $(\mathrm{L})$ & 2.413 .224 & 9.652 .896 \\
4. & Toilet & Unit & 1.815 & - \\
\hline
\end{tabular}

Berdasarkan data tabel 7 di atas dapat dijelaskan bahwa jumlah kebutuhan dasar minimum didapat dari hasil perkalian jumlah penduduk yang terdampak dengan kebutuhan dasar pada setiap satu minggu.Setelah didapat hasil pada satu minggu yaitu Beras 98.010 L, Air Minum 629.805 L, Air Bersih 2.413.224 L, dan Toilet 1.815 unit.Kemudian dari hasil per minggu dikali 4 atau 1 bulan maka didapat hasil yaitu Beras 329.040 L, Air Minum 2.519.220 L, dan Air Bersih 9.652.896.Untuk toilet tetap
1.815 karena toilet bukan bahan habis pakai seperti yang lainnya.

\section{KESIMPULAN}

Dari hasil penelitian dan pembahasan yang telah diuraikan sebelumnya, maka dapat disimpulkan sebagai berikut:

1. Letusan gunungapi Lokon terbagi dalam dua zona kawasan rawan bencana yaitu 
zona rendah pada kawasan rawan bencana I radius (5 $\mathrm{KM}$ ) dan zona tinggi pada kawasan rawan bencanaII radius (3,5 KM). Perkiraan bangunan pada kawasan rawan bencana radius 3,5 KM berjumlah 202 bangunan untuk area ancaman tinggi dan 555 bangunan untuk area ancaman rendah. Sedangkan untuk untuk kawasan rawan bencana radius $5 \mathrm{KM}$ berjumlah 55 bangunan untuk area ancaman tinggi dan 7.300 bangunan untuk area ancaman rendah.

2. Perkiaraan kerugian pada kawasan rawan bencana radius 3,5 KM yaitu 757 bangunan Rp. 36.636.840.000. Dan untuk kawasan rawan bencana radius $5 \mathrm{KM}$ yaitu 7.355 bangunan Rp. 158.730.660.000.

3. Estimasi keterpaparan penduduk yang memerlukan evakuasi sebanyak 36.300 jiwa yang berada pada kawasan rawan bencana rendah hingga tinggi. Sedangkan dari jumlah penduduk yang terdampak maka didapat estimasi kebutuhan dasar minimum beras sebanyak 98.010 liter, air minum sebanyak 629.805 liter, air bersih sebanyak 2.413.224 liter dan toilet sebanyak 1.815 unit.

\section{DAFTAR PUSTAKA}

Ardi S. A. 2017. Analisis Resiko Bencana Erupsi Gunung Merapi di Kecamatan Dukun Kabupaten Magelang [skripsi]. Yogyakarta: Program Studi Pendidikan Geografi, Fakultas Ilmu Sosial, UniversitasNegeri Yogyakarta.

Badan Nasional Penanggulangan Bencana. 2012. Buku Saku Tanggap Tangkas Tangguh Menghadapi Bencana.

Fitri A. N. A. 2017. Analisis Skenario Dampak Keterpaparan dan Mitigasi Bencana Banjir Genangan di Provinsi DKI Jakarta. [skripsi]. Surakarta: Program Studi Geografi, Fakultas Geografi, Universitas Muhammadiyah Surakarta.

Haerani N. dkk. 2010. Studi Terpadu Seismik dan Deformasi di Gunung Lokon, Sulawesi Utara. Jurnal Lingkungan dan Bencana Geolog.Vol 1.

Humanitarian OpenStreetMap Team. Pengembangan Skenario Untuk Rencana Kontijensi, Mengumpulkan Data Spasial dengan OpenStreetMap Unit 1.
Hustin M. dkk.2013. Analisis Biaya Penanganan Kerusakan Jalan di Daerah Banjir Berbasis Quantum GIS-InaSAFE di Kota Makassar. Jurnal Penelitian Jurusan Sipil, FakultasTeknik, Universitas Hasanuddin.

Gunung Lokon, Sulawesi Utara Dikutip 02 Oktober 2019 dari www.vsi.esdm.go.id

Lewu P. A. 2014. Analisis Kawasan Bencana Gunungapi Lokon, Kota Tomohon dan Sekitarnya, Provinsi Sulawesi Utara. Jurnal Mindagi. Vol 8.

Panggula R. J. dkk. 2013. Analisis Biaya Penanganan Kerusakan Jalan di Daerah Banjir Berbasis Quantu m GIS-InaSAFE. Jurusan Teknik Sipil, Fakultas Teknik, Universitas Hasanuddin.

Pradana P. M. C. 2016. Kajian Zonasi Bahaya Erupsi Gunung Merapi Terhadap Permukiman di Kabupaten Magelang [skripsi]. Semarang: Jurusan Geografi, Fakultas Ilmu Sosial, Universitas Negeri Semarang.

Republik Indonesia, Peraturan Menteri Pertanian Nomor 837/KPTS/UM/11/1980 tentang Kriteria dan Tata Cara Penetapan Hutan Lindung.

Sinta, Dewi. 2015. Mitigasi Bencana Lahar Hujan Gunungapi Merapi Berbasis Sistem Informasi Geografi dan Penginderaan Jauh di SUB DAS Kali Putih Kabupaten Magelang [skripsi]. Universitas Muhammadiyah, Surakarta.

Sunarto NS. 2014. Bab II Tinjauan Pustaka Dikutip 03 Oktober 2019 dari digilip.unila.ac.id

Togatorop P. M. dkk. 2016. Pemetaan Potensi Bencana Aliran Lava Gunung Sinabung Menggunakan Citra Aster GDEM. Jurnal Geodesi Undip. Volume 5, Nomor 2. 